\title{
Metal-Dependent Structural Variations and the Peculiarities of Hydrogen- Bonded Networks in the Highly Hydrated Copper(II), Nickel(II) and Palladium(II) Complexes of Bis-Dioxocyclam
}

\author{
Sergey P. Gavrish, ${ }^{\dagger}$ Yaroslaw D. Lampeka, ${ }^{\dagger}$ and Philip Lightfoot ${ }^{*}$
}

${ }^{\dagger}$ L. V. Pisarzhevskii Institute of Physical Chemistry of the National Academy of Sciences of Ukraine, Prospekt Nauki 31, Kyiv 03028, Ukraine

${ }^{\ddagger}$ School of Chemistry and EaStChem, University of St Andrews, St Andrews, KY16 9ST, U.K.

A comparison of the molecular structure of the copper(II), nickel(II) and palladium(II) complexes $\mathrm{M}_{2} \mathrm{~L}^{14 \mathrm{~B}}$ of the bis-dioxocyclam ligand (bis-dioxocyclam, $\mathrm{H}_{4} \mathrm{~L}^{14 \mathrm{~B}}=6,6$ '-bi- $(1,4,8,11$ tetraazacyclotetradecane)-5,5',7,7'-tetraone) determined by single crystal X-ray diffraction with published data for the related open-chain and macrocyclic compounds revealed that the conformations of the binuclear compounds of this type are more sensitive to the nature of the coordinated metal ion as compared to those of their mononuclear analogues. This peculiarity is likely explained by different tolerance of $\mathrm{d}^{9}$ and $\mathrm{d}^{8}$ ions to violations of planarity of the coordinated amide fragment. The preservation of the differences between conformations of the coordination subunits in the bis-complexes and in the corresponding mononuclear species is further confirmed by ${ }^{1} \mathrm{H}$ NMR spectra of the diamagnetic nickel(II) and palladium(II) macrocyclic complexes in aqueous solution. The dicopper(II) complex forms two types of crystals differing in the number of crystalline water molecules and this results in different dimensionality of the water aggregates, i.e., $1 \mathrm{D}$-chains for $\mathrm{Cu}_{2} \mathrm{~L}^{14 \mathrm{~B}} \cdot 9 \mathrm{H}_{2} \mathrm{O}$ vs. $2 \mathrm{D}$-layers for $\mathrm{Cu}_{2} \mathrm{~L}^{14 \mathrm{~B}} \cdot 12 \mathrm{H}_{2} \mathrm{O}$. In spite of similarity of the molecular geometry, packing features and construction of the water aggregates in $\mathrm{Ni}_{2} \mathrm{~L}^{14 \mathrm{~B}} \cdot 12 \mathrm{H}_{2} \mathrm{O}$ and $\mathrm{Pd}_{2} \mathrm{~L}^{14 \mathrm{~B}} \cdot 12 \mathrm{H}_{2} \mathrm{O}$ (2D-layers vs. 3Dnetwork) are unexpectedly dissimilar.

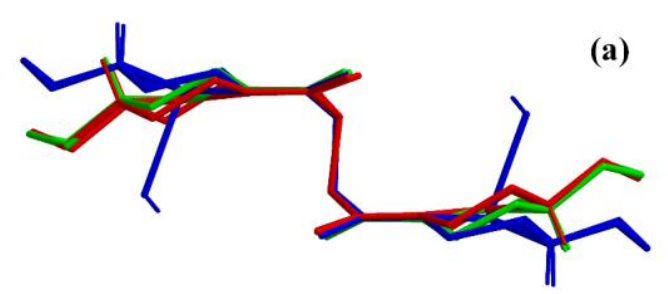

(c)

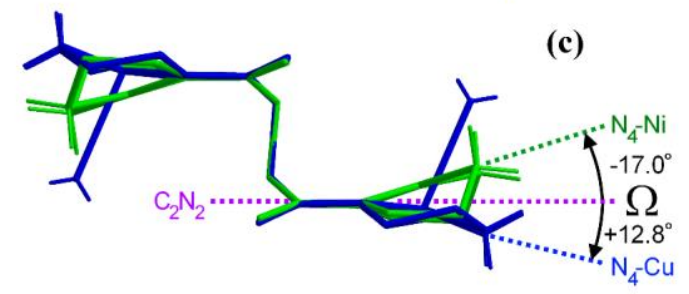

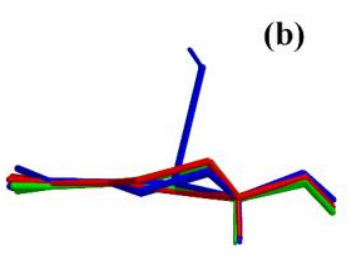

(d)

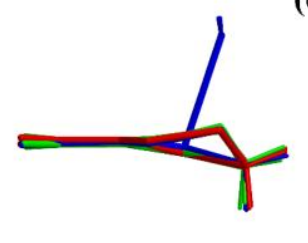

Comparison of the conformations of the complexes of bismacrocyclic (a) and bis(open-chain) (c) ligands with those of their mononuclear analogous (b and d, respectively). Copper(II) compounds are drawn in blue, nickel(II) - in green, and palladium(II) - in red.

\section{Corresponding Author: Prof. Yaroslaw D. Lampeka}

L. V. Pisarzhevskii Institute of Physical Chemistry of the National Academy of Sciences of Ukraine, Prospekt Nauki 31, Kyiv 03028, Ukraine

E-mail: lampeka@ adamant.net;

Phone: +38-044-5252570; Fax: +38-044-5252570. 


\title{
Metal-Dependent Structural Variations and the Peculiarities of Hydrogen- \\ Bonded Networks in the Highly Hydrated Copper(II), Nickel(II) and \\ Palladium(II) Complexes of Bis-Dioxocyclam
}

\author{
Sergey P. Gavrish, ${ }^{\dagger}$ Yaroslaw D. Lampeka, ${ }^{* \dagger}$ and Philip Lightfoot
}

${ }^{\dagger}$ L. V. Pisarzhevskii Institute of Physical Chemistry of the National Academy of Sciences of Ukraine, Prospekt Nauki 31, Kyiv 03028, Ukraine

${ }^{\star}$ School of Chemistry and EaStChem, University of St Andrews, St Andrews, KY16 9ST, U.K.

Corresponding Author*E-mail: lampeka@adamant.net. Fax: +38-044-5252570.

\section{ABSTRACT}

The crystal structures of the copper(II) $\left(\mathrm{Cu}_{2} \mathrm{~L}^{14 \mathrm{~B}} \cdot 9 \mathrm{H}_{2} \mathrm{O}\right.$ and $\left.\mathrm{Cu}_{2} \mathrm{~L}^{14 \mathrm{~B}} \cdot 12 \mathrm{H}_{2} \mathrm{O}\right)$, nickel(II) $\left(\mathrm{Ni}_{2} \mathrm{~L}^{14 \mathrm{~B}} \cdot 12 \mathrm{H}_{2} \mathrm{O}\right)$ and palladium(II) $\left(\mathrm{Pd}_{2} \mathrm{~L}^{14 \mathrm{~B}} \cdot 12 \mathrm{H}_{2} \mathrm{O}\right)$ complexes of the $\mathrm{C}-\mathrm{C}$ linked bisdioxocyclam ligand have been determined by single crystal X-ray diffraction (bis-dioxocyclam, $\mathrm{H}_{4} \mathrm{~L}^{14 \mathrm{~B}} \cdot=6,6^{\prime}$-bi-(1,4,8,11-tetraazacyclotetradecane)-5,5',7,7'-tetraone). Planar coordination environment of the metal(II) ions is formed by $c i s-2 \mathrm{~N}_{\text {amide }}+c i s-2 \mathrm{~N}_{\text {amine }}$ donor atoms.

Additionally, the apical site in the copper(II) complexes is occupied by the water molecule. All complex molecules adopt a 'stretched' conformation with intramolecular metal-metal distances ranging from 6.608 to $7.002 \AA$. The conformations of the macrocyclic subunits in $\mathrm{M}_{2} \mathrm{~L}^{14 \mathrm{~B}}$ reveal considerable variations depending on the metal ion and differ significantly from those of the corresponding mono-macrocyclic dioxocyclam complexes $\mathrm{ML}^{14 \mathrm{M}}$ (dioxocyclam, $\mathrm{H}_{2} \mathrm{~L}^{14 \mathrm{M}} \cdot=$ 1,4,8,11-tetraazacyclotetradecane-5,7-dione) thus resembling the behavior for the open-chain 
analogues. A detailed analysis of the ${ }^{1} \mathrm{H}$ NMR spectra of the diamagnetic nickel(II) and palladium(II) complexes supports preservation of the conformational differences in aqueous solution. Electronic absorption spectra and electrochemical characteristics of the $\mathrm{M}_{2} \mathrm{~L}^{14 \mathrm{~B}}$ complexes are also briefly discussed. Being highly hydrated solids, the bis-macrocyclic compounds are characterized by extended networks of hydrogen bonds. The water molecules form infinite aggregates differing by the structure and dimensionality - 1D chains for $\mathrm{Cu}_{2} \mathrm{~L}^{14 \mathrm{~B}} \cdot 9 \mathrm{H}_{2} \mathrm{O}, 2 \mathrm{D}$ layers for $\mathrm{Cu}_{2} \mathrm{~L}^{14 \mathrm{~B}} \cdot 12 \mathrm{H}_{2} \mathrm{O}$ and $\mathrm{Ni}_{2} \mathrm{~L}^{14 \mathrm{~B}} \cdot 12 \mathrm{H}_{2} \mathrm{O}$, and 3D-network for $\mathrm{Pd}_{2} \mathrm{~L}^{14 \mathrm{~B}} \cdot 12 \mathrm{H}_{2} \mathrm{O}$. 


\section{INTRODUCTION}

In the past years polynuclear complexes have become increasingly dominant in the field of coordination chemistry. Although a significant amount of research is focused on compounds demonstrating rather strong metal-metal interactions, such as ligand-bridged systems and clusters, ${ }^{1}$ there is also interest in another type of complexes in which metal centers are well separated, providing the opportunity for multicenter binding of substrates. To a considerable extent this interest is inspired by the fact that such compounds may serve as models for the charge transfer, electron transport and allosteric behavior found in many metal-containing biochemical systems. $^{2}$

Macrocycles and, in particular, azamacrocycles are considered as useful building blocks for such systems since their metal complexes typically show enhanced kinetic and thermodynamic stabilities. ${ }^{3}$ In addition, the interest in linked macrocyclic ligands was further stimulated by the finding that some bis-macrocyclic derivatives reveal anti-HIV activity. ${ }^{4}$ Depending on the mode of connection (N-N or C-C linking) and the nature of the spacer the inter-metal ion distance and the relative orientation of the macrocyclic rings can be varied and to date a great number of linked azamacrocycles has been reported. ${ }^{5}$

\section{Scheme 1. Complexes of the Malonamide-Derived Ligands}
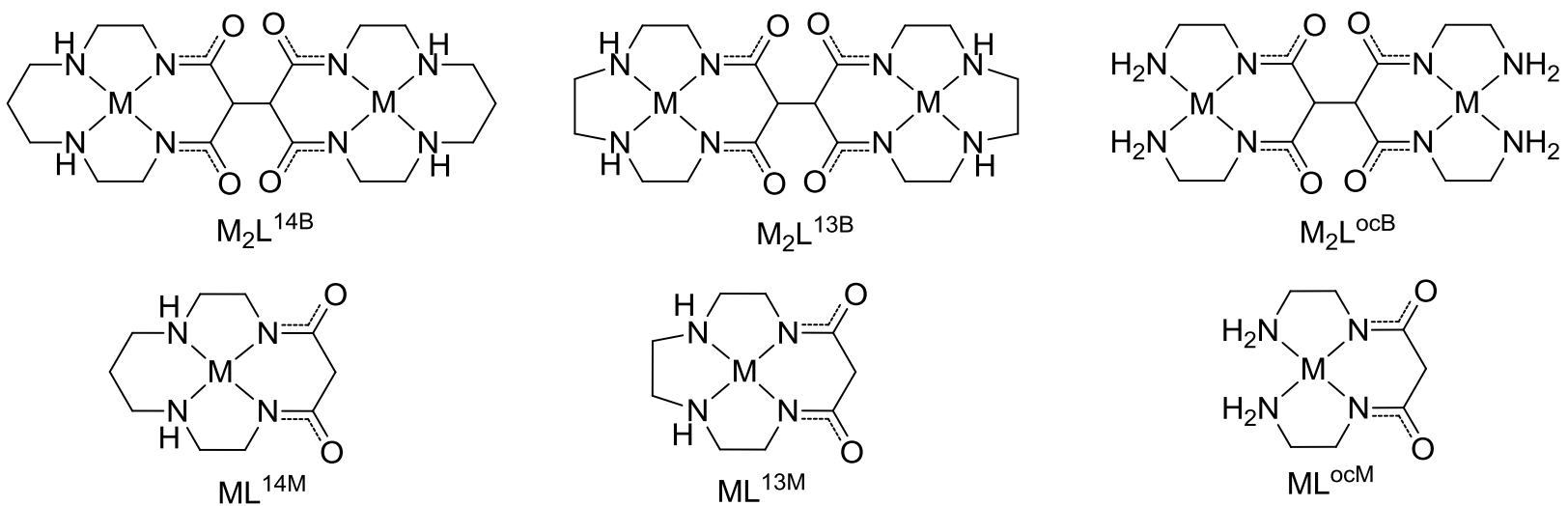

$\mathrm{ML}^{13 \mathrm{M}}$

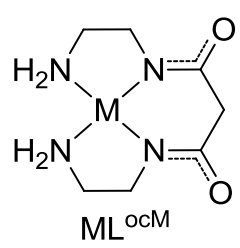


The bis-macrocyclic ligand $\mathrm{H}_{4} \mathrm{~L}^{14 \mathrm{~B}}$ (Scheme 1) prepared using the one-step aminolytic condensation method of Tabushi ${ }^{6}$ was among the first reported C-C linked tetraazamacrocyclic compounds. ${ }^{7}$ The presence of the amide functions introduces a number of specific properties, making ligands of this type resemble oligopeptides ${ }^{8}$ in two respects $-(i)$ incorporation of the metal ion into the macrocyclic cavity requires deprotonation of the amide groups and hence complex formation is strongly $\mathrm{pH}$-dependent; (ii) complexes thus formed show the ability to stabilize uncommon oxidation states such as $\mathrm{Cu}^{\mathrm{III}}$ and $\mathrm{Ni}^{\mathrm{III}} \cdot{ }^{9}$ A detailed investigation carried out on $\mathrm{L}^{14 \mathrm{~B}}$ confirmed formation of the stable electroneutral dicopper(II) complex under mild basic conditions and easy oxidation of the copper ions to the trivalent state in two consecutive oneelectron steps separated by $110 \mathrm{mV}{ }^{7}$ However, attempts to isolate initial dicopper(II) complex as a solid were unsuccessful ${ }^{10}$ and its structure remains unknown. Somewhat surprisingly, complexes of $\mathrm{L}^{14 \mathrm{~B}}$ with other metal ions have not been described so far. At the same time, the crystal structures of a number of binuclear complexes of the 13-membered $\left(\mathrm{L}^{13 \mathrm{~B}}\right)^{11}$ and openchain $\left(\mathrm{L}^{\mathrm{ocB}}\right)^{12-14}$ ligands based on the same bis-malonamide core have been reported.

This series demonstrates interesting variations in the molecular geometry dependent on the nature of the metal ion. Although for the most of complexes a 'stretched' (centrosymmetric) conformation was found, the dinickel(II) complex of $\mathrm{L}^{13 \mathrm{~B}}$ has a principally different 'folded' $\left(\mathrm{C}_{2}\right.$-symmetric) structure. ${ }^{11}$ On the other hand, an analysis reveals remarkable distinction in conformations of the coordinating subunits in the dicopper(II $)^{12}$ and dinickel(II) $)^{14}$ complexes of $\mathrm{L}^{\mathrm{ocB}}$. In turn, the structure of these subunits appears to be rather different from that of the mononuclear $\mathrm{ML}^{\mathrm{ocM}}$ analogues ${ }^{15-17}$ (vide infra).

In order to check whether the noted metal-dependent structural variations have a general character structural investigation of the copper(II), nickel(II) and palladium(II) complexes of $\mathrm{L}^{14 \mathrm{~B}}$ was undertaken, complemented for diamagnetic complexes by a ${ }^{1} \mathrm{H}$ NMR spectroscopic study in solution. The results are compared to our data for the mono-macrocyclic compounds $\mathrm{ML}^{14 \mathrm{M}} \cdot{ }^{15,17,18}$. An additional reason for the interest in this type of compounds arises from the fact 
that they often crystallize as highly hydrated hydrogen-bond-rich solids, e.g. $\mathrm{Ni}_{2} \mathrm{~L}^{\mathrm{ocB}} \cdot 6 \mathrm{H}_{2} \mathrm{O},{ }^{14}$ $\mathrm{Cu}_{2} \mathrm{~L}^{\mathrm{ocB}} \cdot 10 \mathrm{H}_{2} \mathrm{O},{ }^{12} \mathrm{Cu}_{2} \mathrm{~L}^{13 \mathrm{~B}} \cdot 14 \mathrm{H}_{2} \mathrm{O} .{ }^{11}$ Bis-dioxocyclam complexes are not the exception in this respect and hydrogen bonded networks in their crystal structures, formed with the participation of co-crystallized water molecules, are also discussed in this paper.

\section{EXPERIMENTAL SECTION}

Syntheses. The bis-macrocyclic ligand $\mathrm{H}_{4} \mathrm{~L}^{14 \mathrm{~B}}$ was synthesized according to a literature procedure. ${ }^{7}$ Metal(II) complexes of this ligand were isolated as follows.

$\mathrm{Cu}_{2} \mathbf{L}^{\mathbf{1 4 B}} \cdot \mathbf{9 H _ { 2 }} \mathrm{O} \cdot \mathrm{Cu}(\mathrm{OAc})_{2} \cdot \mathrm{H}_{2} \mathrm{O}(178 \mathrm{mg}, 0.89 \mathrm{mmol})$ in $\mathrm{H}_{2} \mathrm{O}(5 \mathrm{~mL})$ was added gradually with stirring to the solution of the ligand $(200 \mathrm{mg}, 0.44 \mathrm{mmol})$ in water $(25 \mathrm{~mL})$. The $\mathrm{pH}$ value was adjusted to $c a$. 8-9 by addition of $\mathrm{NaOH}$ solution. The resulting solution was filtered and concentrated on a rotary evaporator to a volume of $c a .2 \mathrm{ml}$. The blue-violet crystalline solid formed was filtered off and washed with acetone. The product was purified through reprecipitation from aqueous solution with acetone. The solid was filtered off, washed with acetone and air dried. Yield $260 \mathrm{mg}(80 \%)$. Anal.: Calcd. for $\mathrm{C}_{20} \mathrm{H}_{52} \mathrm{Cu}_{2} \mathrm{~N}_{8} \mathrm{O}_{13}: \mathrm{C}, 32.47 ; \mathrm{H}, 7.09$; N, 15.15. Found: C, 32.43; H, 7.08; N, $15.00(\%)$.

$\mathbf{N i}_{2} \mathbf{L}^{14 \mathrm{~B}} \cdot \mathbf{1 2}_{2} \mathbf{O}$. This compound was prepared analogously. The yield of the complex (yellow crystalline solid) using $150 \mathrm{mg}(0.33 \mathrm{mmol})$ of the ligand and $165 \mathrm{mg}(0.66 \mathrm{mmol})$ of $\mathrm{Ni}(\mathrm{OAc})_{2} \cdot 4 \mathrm{H}_{2} \mathrm{O}$ was $135 \mathrm{mg}(52 \%)$. Anal.: Calcd. for $\mathrm{C}_{20} \mathrm{H}_{58} \mathrm{Ni}_{2} \mathrm{~N}_{8} \mathrm{O}_{16}: \mathrm{C}, 30.64 ; \mathrm{H}, 7.46$; , 14.29. Found: C, 30.88; H, 7.38; N, $14.36(\%)$.

$\mathbf{P d}_{2} \mathbf{L}^{\mathbf{1 4 B}} \cdot \mathbf{1 0 H}_{2} \mathbf{O} . \mathrm{K}_{2} \mathrm{PdCl}_{4}(290 \mathrm{mg}, 0.89 \mathrm{mmol})$ in $\mathrm{H}_{2} \mathrm{O}(5 \mathrm{~mL})$ was added gradually with stirring to the solution of the ligand $(200 \mathrm{mg}, 0.44 \mathrm{mmol})$ in water $(25 \mathrm{~mL})$ keeping $\mathrm{pH}$ about 8 by addition of $\mathrm{KOH}$ solution. The resulting yellowish solution was heated and evaporated to a volume of $c a .2 \mathrm{ml}$ (small amount of yellow-brown precipitate formed during evaporation was filtered off). The white crystalline solid formed on cooling was filtered off and washed with a 
small amount of cold water and with acetone. It was then recrystallized from water, washed with acetone and air dried. Yield $144 \mathrm{mg}(39 \%)$. Anal.: Calcd. for $\mathrm{C}_{20} \mathrm{H}_{54} \mathrm{~N}_{8} \mathrm{O}_{14} \mathrm{Pd}_{2}: \mathrm{C}, 28.48 ; \mathrm{H}, 6.45$; N, 13.28. Found: C, 28.22; H, 6.66; N, $13.19(\%)$.

Single crystals suitable for X-ray diffraction analysis were obtained by diffusion of acetone vapor into aqueous solutions of the complexes. In the case of the copper(II) complex along with needle-like crystals having composition identical to that of the bulk sample $\mathrm{Cu}_{2} \mathrm{~L}^{14 \mathrm{~B}} \cdot 9 \mathrm{H}_{2} \mathrm{O}(\mathbf{1 a}-\mathbf{C u})$ another cube-like crystals containing more co-crystallized water molecules $\mathrm{Cu}_{2} \mathrm{~L}^{14 \mathrm{~B}} \cdot 12 \mathrm{H}_{2} \mathrm{O}(\mathbf{1 b}-\mathbf{C u})$ are formed simultaneously. For the nickel(II) complex the composition of the single crystals $\mathrm{Ni}_{2} \mathrm{~L}^{14 \mathrm{~B}} \cdot 12 \mathrm{H}_{2} \mathrm{O}(\mathbf{2}-\mathbf{N i})$ and of the bulk sample is identical, while the crystals of the palladium(II) analogue $\left(\mathrm{Pd}_{2} \mathrm{~L}^{14 \mathrm{~B}} \cdot 12 \mathrm{H}_{2} \mathrm{O}, 3\right.$-Pd $)$ rather quickly lose, in air, two co-crystallized water molecules.

X-ray Data Collection and Structure Determination. Measurements were made on either Bruker AXS SMART 1000 (1a,b-Cu and 3-Pd) or Rigaku AFC7S (2-Ni) diffractometers with graphite monochromated Mo-K $\alpha$ radiation $(\lambda=0.71073 \AA)$. The data were collected using the $\omega-2 \theta$ scan technique for $\mathbf{2}-\mathbf{N i}$ and the $\omega-$ scan technique for other compounds. The intensities were corrected for Lorentz, polarization and absorption effects. The structures were solved by direct methods ${ }^{19}$ and refined by full-matrix, least squares methods based on $F^{2}\left(\right.$ SHELXTL $\left.^{20}\right)$. The non-hydrogen atoms were refined anisotropically. Hydrogen atoms were located by Fourier methods and refined isotropically, except for hydrogen atoms attached to $\mathrm{C}$ and $\mathrm{N}$ for $\mathbf{2}-\mathbf{N i}$ which were placed geometrically and treated as riding atoms. One of the two hydrogen atoms in two co-crystallized water molecules $\left(\mathrm{H}_{2} \mathrm{O}(7)\right.$ and $\left.\mathrm{H}_{2} \mathrm{O}(8)\right)$ present in $\mathbf{1 b}-\mathbf{C u}$ is disordered over two positions. Other crystal data and experimental parameters are summarized in Table 1. 
Table 1. Crystal Data and Structure Refinement for the Bis-Macrocyclic Complexes $M_{2} L^{14 B}$

\begin{tabular}{|c|c|c|c|c|}
\hline & 1a-Cu & 1b-Cu & $2-\mathrm{Ni}$ & 3-Pd \\
\hline empirical formula & $\mathrm{C}_{20} \mathrm{H}_{52} \mathrm{Cu}_{2} \mathrm{~N}_{8} \mathrm{O}_{13}$ & $\mathrm{C}_{20} \mathrm{H}_{58} \mathrm{Cu}_{2} \mathrm{~N}_{8} \mathrm{O}_{16}$ & $\mathrm{C}_{20} \mathrm{H}_{58} \mathrm{Ni}_{2} \mathrm{~N}_{8} \mathrm{O}_{16}$ & $\mathrm{C}_{20} \mathrm{H}_{58} \mathrm{~N}_{8} \mathrm{O}_{16} \mathrm{Pd}_{2}$ \\
\hline formula weight & 739.80 & 793.82 & 784.12 & 879.54 \\
\hline$T(\mathrm{~K})$ & $190(2)$ & $173(2)$ & $150(2)$ & $173(2)$ \\
\hline crystal system & monoclinic & monoclinic & monoclinic & triclinic \\
\hline space group & $C 2 / c$ & $C 2 / c$ & $P 2{ }_{1} / c$ & $P(-) 1$ \\
\hline$a(\AA)$ & 24.3131(14) & $25.5162(13)$ & $11.199(7)$ & $11.5297(3)$ \\
\hline$b(\AA)$ & $8.5468(5)$ & $8.4920(4)$ & $12.249(7)$ & $12.4137(3)$ \\
\hline$c(\AA)$ & $16.2170(9)$ & $16.4462(8)$ & $12.816(5)$ & $14.2576(2)$ \\
\hline$\alpha(\operatorname{deg})$ & & & & $92.1490(10)$ \\
\hline$\beta(\operatorname{deg})$ & $109.9380(10)$ & $106.0560(10)$ & $99.99(4)$ & $110.6110(10)$ \\
\hline$\gamma(\operatorname{deg})$ & & & & $112.098(2)$ \\
\hline$V\left(\AA^{3}\right)$ & $3167.9(3)$ & $3424.6(3)$ & $1731.4(16)$ & $1735.41(7)$ \\
\hline$Z$ & 4 & 4 & 2 & 2 \\
\hline$D_{\text {calc }}\left(\mathrm{g} \mathrm{cm}^{-3}\right)$ & 1.551 & 1.540 & 1.504 & 1.683 \\
\hline$\mu\left(\mathrm{mm}^{-1}\right)$ & 1.414 & 1.320 & 1.164 & 1.114 \\
\hline$F(000)$ & 1560 & 1680 & 836 & 908 \\
\hline reflections collected/ & $21400 / 5522$ & $20964 / 6504$ & $3209 / 3047$ & $35164 / 13060$ \\
\hline unique & $\left(R_{\mathrm{int}}=0.0337\right)$ & $\left(R_{\mathrm{int}}=0.0221\right)$ & $\left(R_{\mathrm{int}}=0.1931\right)$ & $\left(R_{\mathrm{int}}=0.0305\right)$ \\
\hline $\begin{array}{l}\text { data / restraints / } \\
\text { parameters }\end{array}$ & $5522 / 0 / 299$ & $6504 / 0 / 328$ & 3047 / 2 / 244 & 13060 / 0 / 647 \\
\hline GOF on $F^{2 a}$ & 1.073 & 1.038 & 1.088 & 1.035 \\
\hline$R_{1}[I>2 \sigma(I)]^{b}$ & 0.0274 & 0.0230 & 0.0766 & 0.0263 \\
\hline$w R_{2}(\text { all data })^{c}$ & 0.0738 & 0.0656 & 0.2716 & 0.0768 \\
\hline
\end{tabular}


Spectral and Electrochemical Measurements. ${ }^{1} \mathrm{H}$ NMR spectra of the complexes in $\mathrm{D}_{2} \mathrm{O}$ solution were measured at $303 \mathrm{~K}$ on a Bruker Avance $500 \mathrm{MHz}$ spectrometer and referenced to the solvent signal $(\delta 4.720 \mathrm{ppm})$. The analysis was performed by means of computer simulation with gNMR 3.6 software. ${ }^{21}$ Electronic absorption spectra were recorded on a Specord 210 (Zeiss) spectrometer. Cyclic voltammograms were measured using a standard three electrode scheme with glassy carbon working, Pt auxiliary and saturated calomel (SCE) reference electrodes as described elsewhere. ${ }^{22}$

\section{RESULTS AND DISCUSSION}

Molecular Structure of the Complexes. Perspective views of the bis-macrocyclic complexes under consideration with the atom numbering scheme employed are shown in Figure 1. Selected parameters characterizing the metal(II) coordination polyhedra are collected in Table 2. Similarly to other compounds of this type ${ }^{11-14}$ (except for $\left.\mathrm{Ni}_{2} \mathrm{~L}^{13 \mathrm{~B}}\right)^{11}$ the bis-macrocyclic ligand in all complexes adopts a 'stretched' conformation with the $\mathrm{C}-\mathrm{C}$ bond joining macrocyclic subunits being slightly elongated ( $c a .1 .57 \AA$ ) as compared to the normal value (ca. $1.54 \AA$ ). The dicopper and dinickel complexes possess an inversion center in the middle of this bond; the subunits in the dipalladium one are not strictly equivalent but the molecule is actually very close to centrosymmetric (Table 2). In all compounds the metal ion is coordinated in a planar manner by two deprotonated amide and two secondary amine nitrogen donor atoms with hydrogen atoms of the latter directed 'outside', i.e. opposite to bridging $\mathrm{C}-\mathrm{C}$ bond, in contrast to complexes of the 13-membered analogues. ${ }^{11}$ 


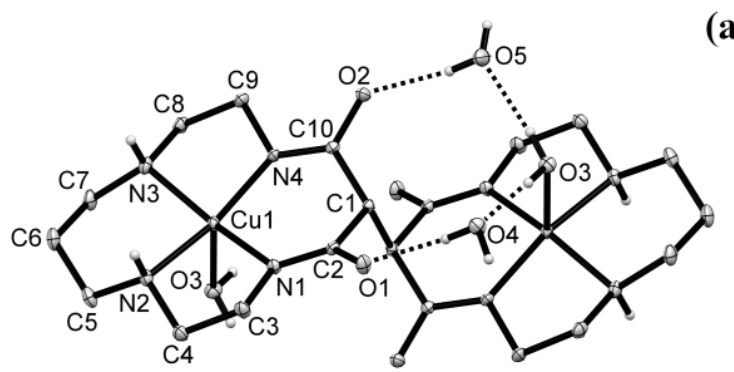

(a)

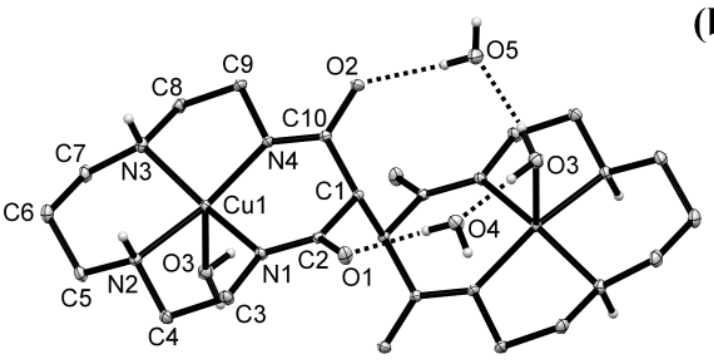

(b)

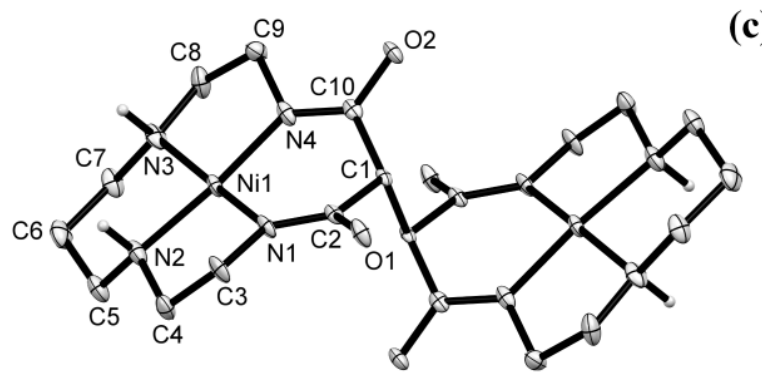

(c)

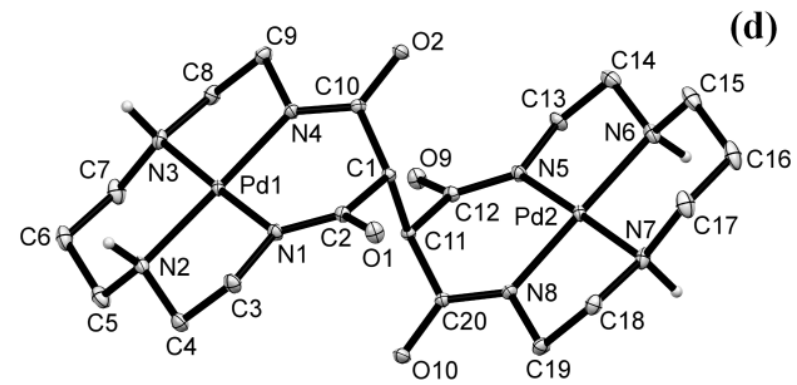

Figure 1. Perspective views of the bis-macrocyclic complexes: 1a-Cu (a), 1b-Cu (b), 2-Ni (c) and 3-Pd (d) with the atom numbering scheme. Thermal ellipsoids are drawn at the $30 \%$ probability level; hydrogen atoms attached to carbon are not shown.

The nickel(II) and palladium(II) complexes are four-coordinate, while the coordination polyhedron of the copper(II) ions includes an apical water molecule $\mathrm{H}_{2} \mathrm{O}(3)$ additionally linked to amide oxygen atoms of another macrocyclic subunit via bridging $\mathrm{H}_{2} \mathrm{O}(4)$ and $\mathrm{H}_{2} \mathrm{O}(5)$ molecules with the formation of an intramolecular H-bonded cyclic system (Figures 1a, 1b). An analogous structural motif is also present in all dicopper(II) complexes of this type. ${ }^{11-13}$

The conformations of the 14-membered macrocyclic subunits in all complexes are close to mirror-symmetric, therefore the deviations of the nitrogen donor atoms from the mean $\mathrm{N}_{4}$ plane are very small (r.m.s. $0.005 \AA$ for $\mathbf{2 - N i}$ and 3-Pd and $0.007 \AA$ for both $\mathbf{1 a}, \mathbf{b}-\mathbf{C u}$ ). The copper(II) ion is displaced from the mean $\mathrm{N}_{4}$-plane towards apical donor by 0.25 (1a-Cu) and $0.23 \AA$ (1b-Cu) which exceeds substantially analogous parameters for square-planar 2-Ni $(0.10$ $\AA)$ and 3-Pd $(0.03 \AA)$. In all cases this displacement is larger than in the mono-macrocyclic analogues $\left(0.14,0.05\right.$ and $0.01 \AA$, respectively).${ }^{15,17,18}$ It is worth noting that the deviations from 
the $\mathrm{N}_{4}$-plane for the entire series, including nickel(II) and palladium(II) complexes, can be accurately predicted based on the values of 'in-plane' characteristics, i.e. the sum of bite angles around the metal ion and $\mathrm{M}-\mathrm{N}$ distances, using expression proposed recently for copper(II) chromophores $^{15}$ (see Table S1 and Figure S1 in the Supporting Information).

Table 2. Selected Interatomic Distances (Å) and Angles (deg) of the Metal(II) Coordination Polyhedra

\begin{tabular}{lllll}
\hline & \multicolumn{1}{c}{ 1a-Cu } & \multicolumn{1}{c}{$\mathbf{1 b - C u}$} & \multicolumn{1}{c}{$\mathbf{2 - N i}$} & 3-Pd $^{\text {a) }}$ \\
\hline $\mathrm{M}-\mathrm{N} 1$ & $1.952(1)$ & $1.948(1)$ & $1.864(6)$ & $1.983(1) ; 1.981(1)$ \\
$\mathrm{M}-\mathrm{N} 4$ & $1.951(1)$ & $1.951(1)$ & $1.874(5)$ & $1.982(1) ; 1.981(1)$ \\
$\mathrm{M}-\mathrm{N} 2$ & $2.020(1)$ & $2.015(1)$ & $1.937(6)$ & $2.048(1) ; 2.049(1)$ \\
$\mathrm{M}-\mathrm{N} 3$ & $2.042(1)$ & $2.045(1)$ & $1.944(7)$ & $2.048(1) ; 2.048(1)$ \\
$\mathrm{Cu}-\mathrm{O}\left(\mathrm{H}_{2} \mathrm{O}\right)$ & $2.316(1)$ & $2.432(1)$ & & - \\
$\mathrm{N} 1-\mathrm{M}-\mathrm{N} 4$ & $94.76(4)$ & $94.86(3)$ & $93.7(2)$ & $95.36(4) ; 95.53(4)$ \\
$\mathrm{N} 1-\mathrm{M}-\mathrm{N} 2$ & $85.01(4)$ & $85.10(3)$ & $86.6(2)$ & $84.00(5) ; 83.60(5)$ \\
$\mathrm{N} 3-\mathrm{M}-\mathrm{N} 4$ & $84.69(5)$ & $84.88(3)$ & $87.0(2)$ & $83.39(4) ; 83.63(5)$ \\
$\mathrm{N} 2-\mathrm{M}-\mathrm{N} 3$ & $91.99(5)$ & $92.01(3)$ & $92.1(2)$ & $97.21(5) ; 97.19(5)$ \\
\hline
\end{tabular}

a) Two values in the column refer to the atoms related by 'inversion', e.g. Pd1-N1; Pd2-N5 etc.

Metal-nitrogen distances (Table 2) fall in the range typical of compounds of this type with common trend of $\mathrm{M}-\mathrm{N}_{\text {amide }}$ bonds involving negatively charged nitrogen atoms being considerably shorter than $\mathrm{M}-\mathrm{N}_{\mathrm{amine}}$ ones. These bond lengths are close, though not identical, to those found for the mono-macrocyclic analogues (see Table S1 in the Supporting Information). The shortest M-N bonds are characteristic of the nickel(II) complexes while the longest - of the palladium(II) ones, for the latter bond lengths are not too different from those in the copper(II) species. 
Despite the close similarity in M-N distances, the conformations adopted by the macrocyclic subunits in binuclear compounds $\mathrm{M}_{2} \mathrm{~L}^{14 \mathrm{~B}}$ are significantly different from those in mono-macrocyclic complexes $\mathrm{ML}^{14 \mathrm{M}}$ and reveal a much stronger dependence on the nature of the metal ion. An analogous tendency is even more obvious in the series of complexes with open-chain ligands (Figure 2).
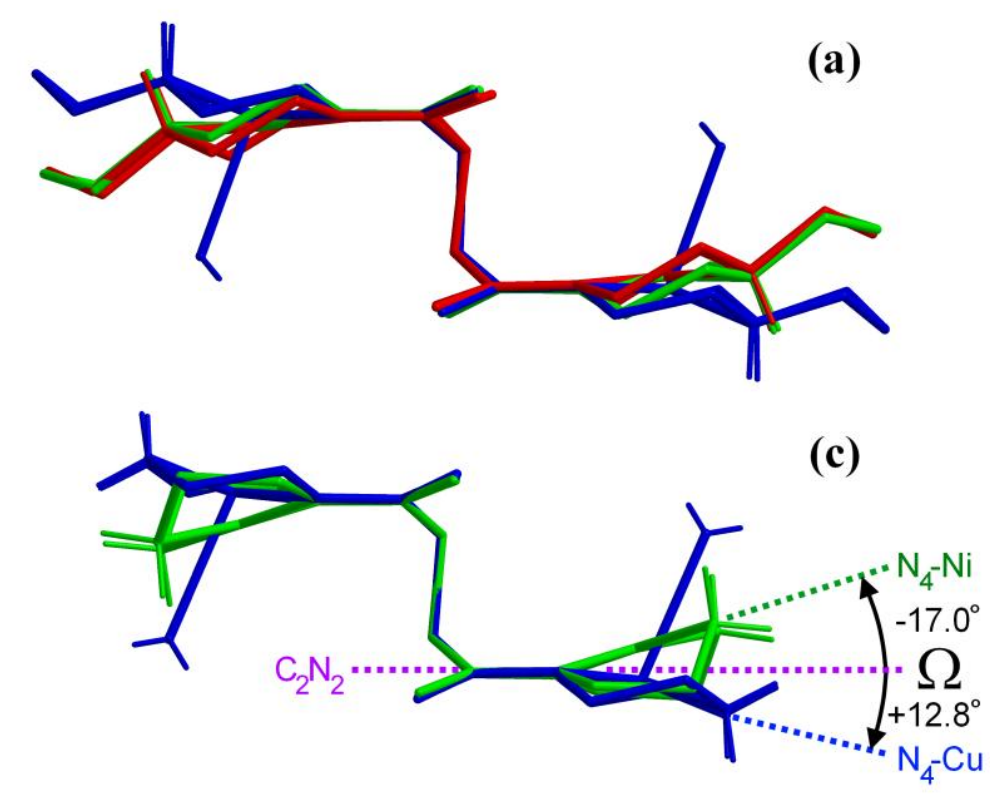

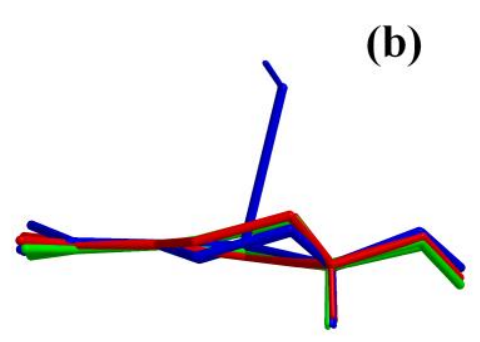

(d)

Figure 2. Comparison of the conformations of the complexes of bis-macrocyclic (a) and bis(open-chain) (c) ligands with those of their mononuclear analogous (b and d, respectively). Copper(II) compounds are drawn in blue, nickel(II) - in green, and palladium(II) - in red.

The distinction in the geometry of the binuclear complexes can be characterized in terms of the angle $\Omega$ between the $\mathrm{C}_{2} \mathrm{~N}_{2}$-plane of the malonamide fragment (i.e. $\mathrm{C}(2)-\mathrm{N}(1)-\mathrm{C}(10)-\mathrm{N}(4)$ ) and the $\mathrm{N}_{4}$-plane of the coordination unit (Figure 2, Table 3). As can be seen, the changes of this angle in the $\mathrm{M}_{2} \mathrm{~L}^{14 \mathrm{~B}}$. series approach $20^{\circ}$ and, as a consequence, the intramolecular metal-metal distances reduce from $6.941(\mathbf{1 a}-\mathbf{C u})$ and $7.002(\mathbf{1 b}-\mathbf{C u})$ to $6.672(\mathbf{2}-\mathbf{N i})$ and $6.608 \AA$ (3-Pd). In the case of $\mathrm{Ni}_{2} \mathrm{~L}^{\mathrm{ocB}} \mathrm{N}_{4}$-plane is moved still further, by $c a$. $30^{\circ}$ with respect to its position in $\mathrm{Cu}_{2} \mathrm{~L}^{\mathrm{ocB}}$, resulting in a shortening of the intramolecular M-M distance from 6.912 to $6.371 \AA \AA^{12,14}$ 
Table 3. The Angles $\Omega(\mathrm{deg})$ between the Malonamide $\mathrm{C}_{2} \mathbf{N}_{2}$ and Coordination $\mathrm{N}_{4}$-planes and Dunitz Amide Non-Planarity Parameters $\chi_{\mathrm{N}}(\mathrm{deg})$ in Parentheses ${ }^{\mathrm{a})}$

\begin{tabular}{ccccc}
\hline & $\mathrm{M}_{2} \mathrm{~L}^{14 \mathrm{~B}}$ & $\mathrm{ML}^{14 \mathrm{M}}$ & $\mathrm{M}_{2} \mathrm{~L}^{\mathrm{ocB}}$ & $\mathrm{ML}^{\mathrm{ocM}}$ \\
\hline $\mathrm{Cu}(\mathrm{II})$ & $+12.3(20.3)$ for 1a-Cu & $+5.7(8.0)$ & $+12.8(23.2)$ & $+12.1(8.2)$ \\
& $+13.8(21.5)$ for $\mathbf{1 b}-\mathbf{C u}$ & & & \\
$\mathrm{Ni}(\mathrm{II})$ & $-5.7(9.0)$ & $+9.2(4.6)$ & $-17.0(5.5)$ & $+11.1(9.1)$ \\
$\mathrm{Pd}(\mathrm{II})$ & $-4.8(5.1)$ & $+6.4(4.0)$ & - & $+11.1(11.1)$ \\
\hline
\end{tabular}

a) $\chi_{N}$ is the angle between substituents at $N_{\text {amide }}(M$ and $C$ ) on a Newman projection down the $\mathrm{N}_{\text {amide }}-\mathrm{C}_{\text {amide }}(=\mathrm{O})$ bond; ${ }^{23}$ averaged absolute values are given.

Another consequence of such a 'rotation' of the $\mathrm{N}_{4}$ plane is the change of the conformation of the malonamide chelate ring from 'half-chair' for copper to 'boat' for nickel and palladium. It is accompanied by a considerable reduction of the degree of pyramidalization of the amide nitrogen atoms in the complexes of $\mathrm{d}^{8}$ ions, as characterized by the Dunitz amide nonplanarity parameter $\chi_{\mathrm{N}}{ }^{23}$ (Table 3). Large deviations from planarity of $\mathrm{sp}^{2}$-hybridized $\mathrm{N}_{\text {amide }}$ centers are expected to be energetically unfavorable and thus the conformations of the nickel(II) and palladium(II) species seem to be preferable from this point of view. It should be noted that $\chi_{\mathrm{N}}$ values as high as $20^{\circ}$ in case of copper(II) are not unusual and have been observed for a number of compounds. ${ }^{15}$

The aforementioned effects are missing or strongly reduced for mononuclear complexes. This is especially evident when compounds of the open-chain ligands are considered. As can be seen from Figure 2d, ML ${ }^{\mathrm{ocM}}$ complexes demonstrate remarkable structural similarity. It is worth to note that the $\Omega$ values in this case are close to that in dicopper complexes but, nevertheless, this does not lead to large deviations of the amide nitrogen atoms from planarity. Apparently, this is related to essentially different conformations of chelate rings typical of these species, i.e. 
unusual almost flat 6-membered malonamide chelate cycle combined with lateral 5-membered chelate rings in specific 'half-envelope' conformation (see Figure S2 in the Supporting Information for the structure of the lateral rings). Basically, the same concerns monomacrocyclic complexes, with $\mathrm{CuL}^{14 \mathrm{M}}$ possessing less planar malonamide ring.

On the other hand, just essentially non-planar structure of the malonamide ring is characteristic for all binuclear complexes under consideration. It is necessary to note that 'folding' of the malonamide chelate cycle seems to be a general consequence of substitution at C1 position. Since the degree of 'folding' is not critically dependent on the nature of the substituent, ${ }^{15}$ the binuclear structure of the compounds itself (i.e. the second subunit as a substituent) is hardly important in this respect. In this case the gauche conformations of the lateral 5-membered chelate rings are generally typical with one exception represented by $\mathrm{Ni}_{2} \mathrm{~L}^{\text {ocB }}$.

Crystal Packing of the Bis-Macrocyclic Complexes. A distinctive feature of the crystal structures of the bis-macrocyclic compounds $\mathbf{1}-\mathbf{3}$ is the lack of the direct $\mathrm{NH} \cdots \mathrm{O}=\mathrm{C}$ hydrogen bonds between complex molecules. Instead, the co-crystallized water molecules, present in large amounts, play a key role in 'gluing' the structures via numerous H-bond contacts. In all cases these water molecules form infinite aggregates of different structures with the dimensionality ranging from 1 for $\mathbf{1 a - C u}$ to 3 for 3-Pd.

The two types of crystals isolated for the copper(II) complex (i.e., 1a-Cu and $\mathbf{1 b}-\mathbf{C u}$ ) belong to the same space group and are characterized by similar values of unit cell parameters (see Table 1). Both are built of similar columns of bis-macrocyclic molecules running along $b$ axis, though differently oriented in the crystal structures (Figures 3a, 3b). Amide oxygen atoms $\mathrm{O}(1)$ of the adjacent complex molecules in these columns are bridged by water molecules $\mathrm{H}_{2} \mathrm{O}(4)$ to yield 4-membered cyclic systems $\mathrm{O}(1)-\mathrm{O}(4)-\mathrm{O}(1)-\mathrm{O}(4)$ and this bonding is reinforced by $\mathrm{H}_{2} \mathrm{O}(6)$ molecules joining $\mathrm{O}(4)$ and amide oxygen atom $\mathrm{O}(2)$ (Figures $3 \mathrm{c}, 3 \mathrm{~d}$ ). Therewith, Hbond networks formed with the participation of water molecules $\mathrm{H}_{2} \mathrm{O}(3)-\mathrm{H}_{2} \mathrm{O}(6)$ are virtually 
the same in both cases. (For symmetry operations relating atoms involved in hydrogen bonding and H-bond parameters in this and other cases see Tables S2 - S5 in the Supporting Information).
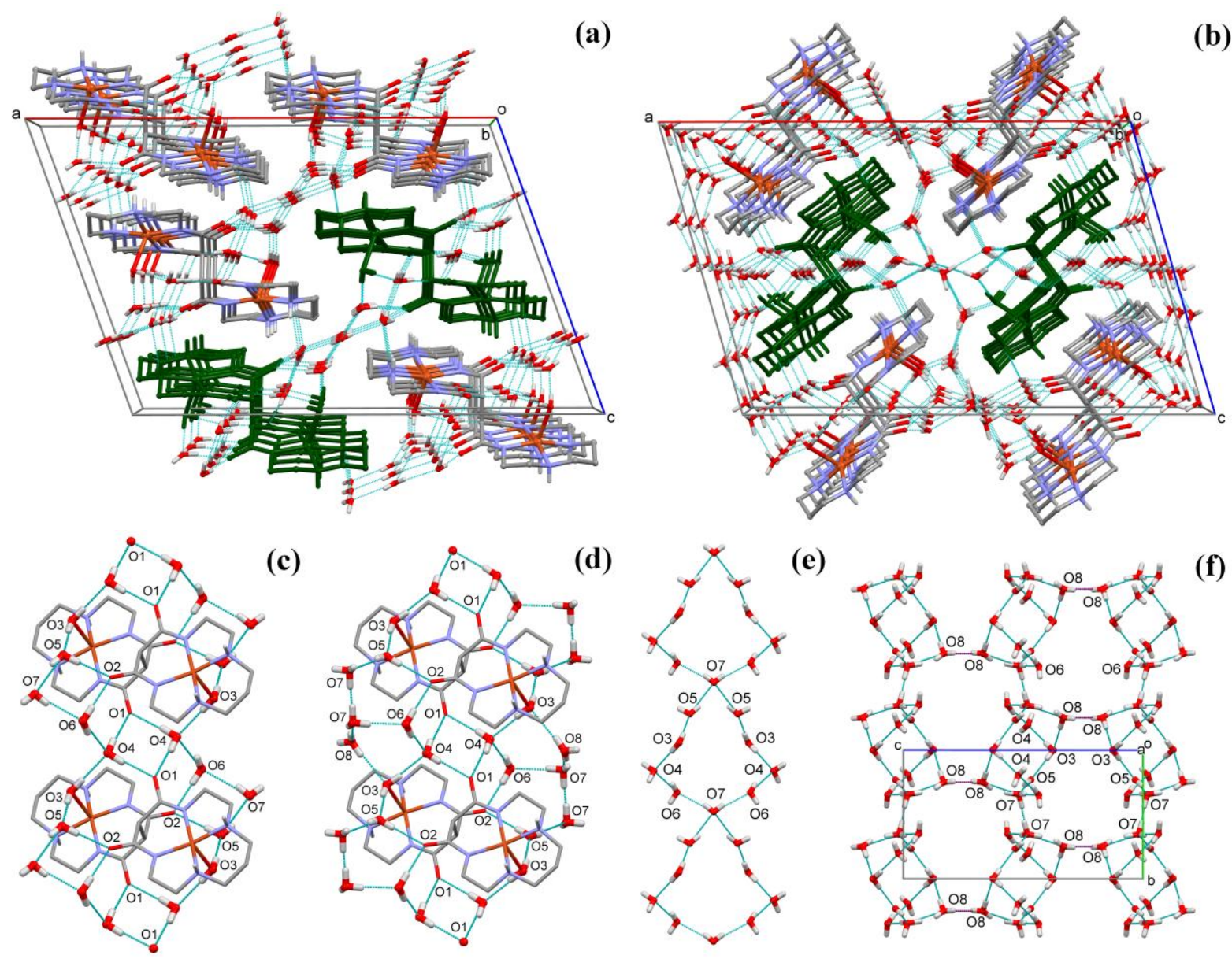

(c)

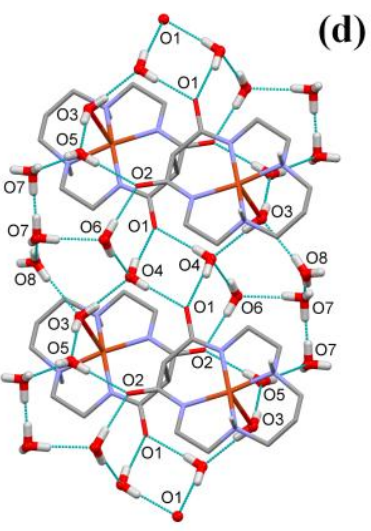

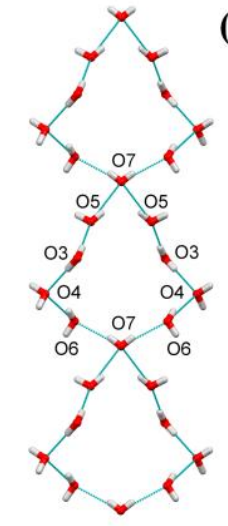

(e)

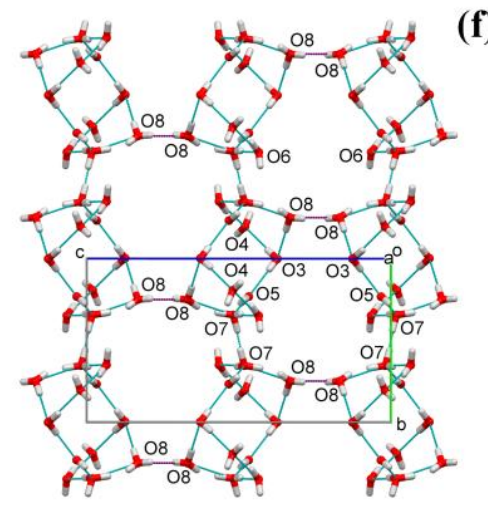

Figure 3. Crystal structures of the copper(II) compounds $\mathbf{1 a - C u}$ (a) and $\mathbf{1 b}-\mathbf{C u}$ (b) as viewed down the $b$-axis; bonding between $\mathrm{Cu}_{2} \mathrm{~L}^{14 \mathrm{~B}}$ units within columns in the structures of $\mathbf{1 a - C u}$ (c) and $\mathbf{1 b}-\mathbf{C u}(\mathrm{d})$; H-bonded water networks in the crystal structures of $\mathbf{1 a - C u}(\mathrm{e})$ and $\mathbf{1 b}-\mathbf{C u}(\mathrm{f})$.

In both structures half-period shifted in $c$-direction columns are joined by means of N(2)$\mathrm{H} \cdots \mathrm{O}(6) \mathrm{H}$-bonds. Due to different orientation in the crystal, another kind of contact, via $\mathrm{H}_{2} \mathrm{O}(7)$ molecules, links columns shifted along a diagonal in the structure $\mathbf{1 a - C u}$ and along the $a$-axis in the structure 1b-Cu (highlighted in Figures 3a, 3b; see also Figure S3 in the Supporting 
Information). In the first case single $\mathrm{H}_{2} \mathrm{O}(7)$ molecules are located on a two-fold rotation axis, whereas in the second case they are replaced by inversion related pairs $\mathrm{H}_{2} \mathrm{O}(7)-\mathrm{H}_{2} \mathrm{O}(7)$. The crystal structure of $\mathbf{1 b}-\mathbf{C u}$ includes also additional water molecules $\mathrm{H}_{2} \mathrm{O}(8)$ bridging $\mathrm{H}_{2} \mathrm{O}(7)$ and axially coordinated $\mathrm{H}_{2} \mathrm{O}(3)$. They play an important role in the formation of the $2 \mathrm{D}$ water network by joining $\mathrm{H}$-bonded water chains into sheets parallel to $b c$-plane due to interaction between symmetry related $\mathrm{H}_{2} \mathrm{O}(8)$ molecules as shown in Figure 3f. In contrast, only one dimensional fir-tree-like structures running along $b$-axis are formed by water molecules in the case of 1a-Cu (Figure 3e).

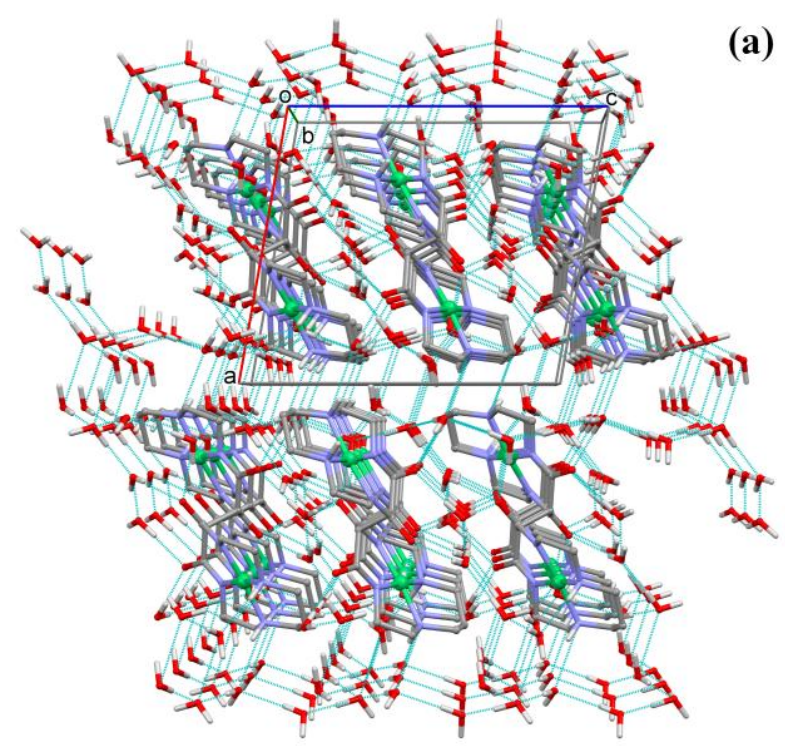

(a)

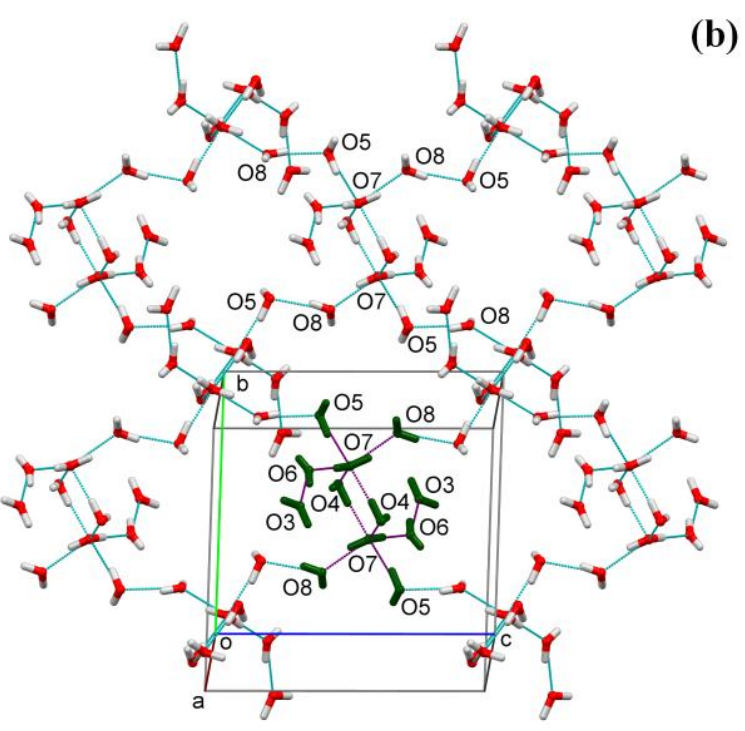

Figure 4. Crystal structure of $\mathbf{2}-\mathbf{N i}$ as viewed down the $b$-axis (a) and H-bonded water layer viewed down the $a$-axis (b).

Analogously to copper(II) compounds, the crystal structure of 2-Ni (Figure 4a) is built of columns of complex molecules running along $b$-axis, though with considerably increased spacing between them (lattice period $12.25 \AA$ vs. ca. $8.5 \AA$ for 1-Cu). As a building block of the $\mathrm{H}$-bonded water network in this case an $\left(\mathrm{H}_{2} \mathrm{O}\right)_{12}$ aggregate based on the 4-membered cyclic structure $\mathrm{O}(4)-\mathrm{O}(7)-\mathrm{O}(4)-\mathrm{O}(7)$ with three 'tails' $\left(\mathrm{H}_{2} \mathrm{O}(5), \mathrm{H}_{2} \mathrm{O}(8)\right.$ and $\left.\mathrm{H}_{2} \mathrm{O}(6)-\mathrm{H}_{2} \mathrm{O}(3)\right)$ at each 
$\mathrm{H}_{2} \mathrm{O}(7)$ can be considered. H-bonds between $\mathrm{H}_{2} \mathrm{O}(5)$ and $\mathrm{H}_{2} \mathrm{O}(8)$ join water clusters into 2D water sheets parallel to $b c$-plane (Figure $4 b$ ), while the $\mathrm{H}_{2} \mathrm{O}(6)-\mathrm{H}_{2} \mathrm{O}(3)$ 'tails' remain pendant. These water aggregates provide the links between complex molecules both within and between neighboring columns (see Figure S4 in the Supporting Information).

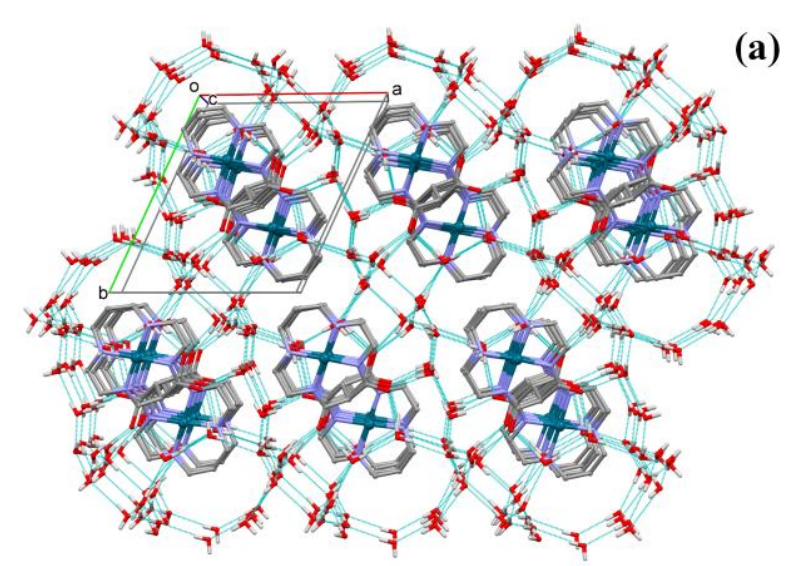

(a)

(b)
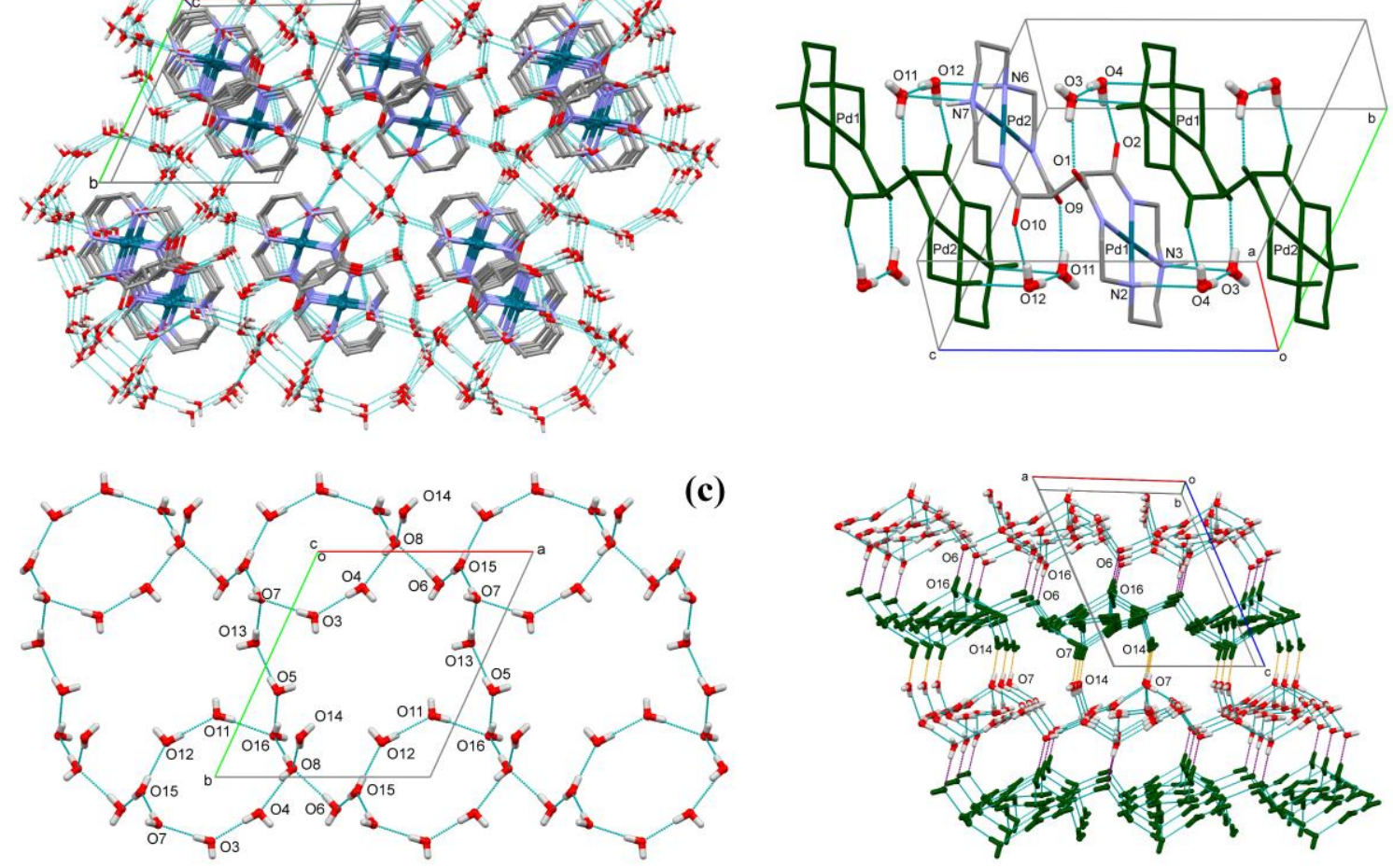

(c)

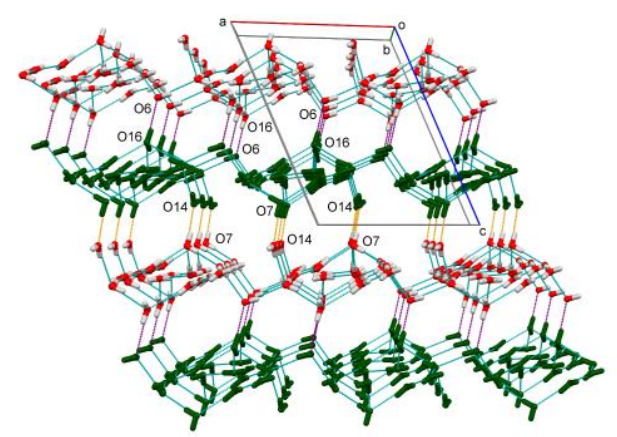

(d)

Figure 5. Crystal structure of 3-Pd as viewed down the $c$-axis (a); the structure of a single column (b); H-bonded water layer (c); 3D water structure resulting from linking between water layers (d).

The structure of the triclinic crystals of 3-Pd can be described in several ways. The best one, in our opinion, is its treatment as built of columns or stacks of alternating (related by inversion operation) bis-macrocyclic units running along the $c$-axis (Figures $5 \mathrm{a}, 5 \mathrm{~b}$ ). The peculiarity of this structure distinguishing it from the compounds discussed above is that the water molecules form a 3D-network. It can be described as built of alternating 2D-layers parallel 
to the $a b$-plane (Figure $5 \mathrm{~d}$ ). Each of these layers is composed of the fused 18 - and 8-membered water rings (Figure 5c). The 18-membered rings are 'wrapped' around bis-macrocyclic units forming $\mathrm{H}$-bonds to amide oxygen atoms, while the 8-membered rings join four neighboring complex molecules via $\mathrm{H}$-bonds to amide oxygen and amine nitrogen atoms (Figure S5 in the Supporting Information). Water layers are interlinked in the $c$-direction through $\mathrm{O}(16)-\mathrm{H} \cdots \mathrm{O}(6)$ and $\mathrm{O}(7)-\mathrm{H} \cdots \mathrm{O}(14)$ contacts at opposite sides of the sheets (Figure $5 \mathrm{~d}$ ). As a result a number of additional cyclic water structures is formed, i.e. 6-, 10- and 12-membered rings originating from $\mathrm{H}_{2} \mathrm{O}(6)-\mathrm{H}_{2} \mathrm{O}(16)$ linking and 10-, 10- and 12-membered rings from $\mathrm{H}_{2} \mathrm{O}(7)-\mathrm{H}_{2} \mathrm{O}(14)$ linking (see Figure S6 in the Supporting Information).

${ }^{1}$ H NMR Spectra. The structural differences in the solid state, described above, are conformational in nature and it is not obvious whether they will be retained in solution. In case of the diamagnetic species the information on the solution structure can be provided by NMR spectroscopy, as it has already been done for the mono-macrocyclic analogues. ${ }^{17,18}$ Therefore detailed ${ }^{1} \mathrm{H}$ NMR investigation of the bis-macrocyclic nickel(II) and palladium(II) complexes was undertaken to clarify this problem.

The experimental ${ }^{1} \mathrm{H}$ NMR spectra of 2-Ni and 3-Pd are shown in Figures 6a, 6c. First of all, it should be noted that the spectra of both complexes comprise excess signals of obviously lower intensity. These signals did not substantially decreased after recrystallization and may refer, in our opinion, to the species possessing another conformation $\left(\mathrm{C}_{2}\right.$-symmetric, gauche arrangement of subunits with respect to the $\mathrm{C}-\mathrm{C}$ bond) similar to that found for $\mathrm{Ni}_{2} \mathrm{~L}^{13 \mathrm{~B}} \cdot{ }^{11}$ Major multiplets in the spectra were successfully reproduced by simulation (Figures 6b, 6d) with the values of chemical shifts and coupling constants listed in Tables S6 and S7 in the Supporting Information. 

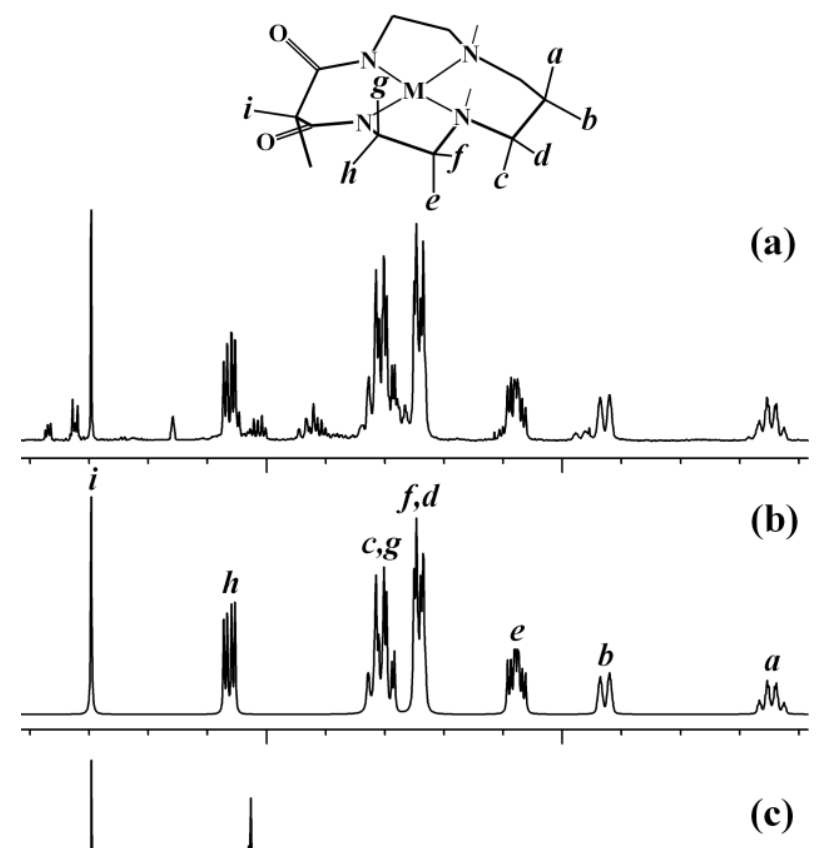

c)

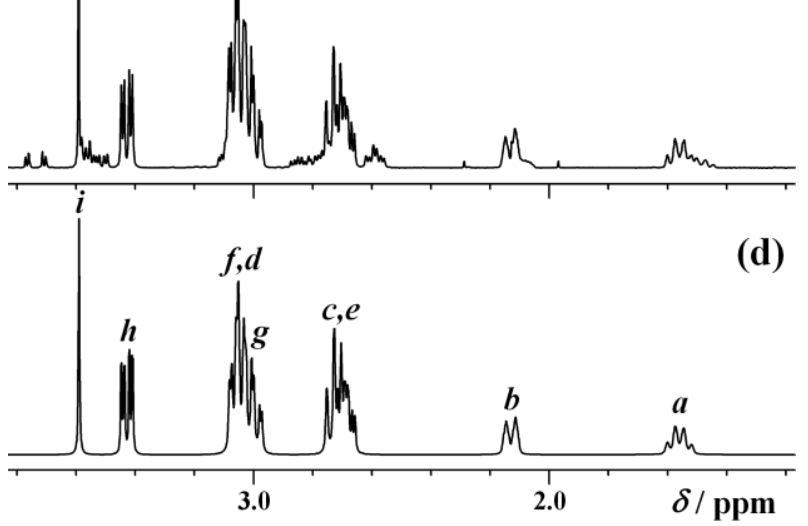

Figure 6. ${ }^{1} \mathrm{H}$ NMR spectra $(500 \mathrm{MHz})$ of the bis-macrocyclic complexes in $\mathrm{D}_{2} \mathrm{O}$ solution: 2 -Ni ( $\mathrm{a}$ - experimental, $\mathrm{b}$ - simulated); 3-Pd (c-experimental, $\mathrm{d}$ - simulated).

The spectrum of 3-Pd as a whole is considerably shifted downfield as compared to that of 2-Ni. The averaged shift of methylene protons of $c a .0 .38 \mathrm{ppm}$ is similar to that observed for the mono-macrocyclic compounds. ${ }^{17}$ Somewhat surprisingly, the position of the low-field singlets assigned to protons in the malonamide ring $(i)$ remains almost unchanged. The significantly different appearance of the spectra is due to essentially non-uniform character of chemical shifts variation. The most different from the averaged value are the shifts for the protons $\boldsymbol{f}, \boldsymbol{d}$ and $\boldsymbol{e}$ (larger) and $\boldsymbol{c}$ (lower). Except for the proton $\boldsymbol{e}$, this behavior is common for both bis- and mono- 
macrocyclic complexes. The differences between bis- and mono-macrocyclic complexes of the same metal ion are less significant. The common effect is some deshielding of the proton $c$ in the bis-complexes and the distinction - increased shielding of the proton $\boldsymbol{e}$ in $\mathbf{2}-\mathbf{N i}$ and of the proton $\boldsymbol{h}$ in 3-Pd as compared to $\mathrm{ML}^{14 \mathrm{M}}$.

Unfortunately, the reasons affecting proton chemical shifts in metal complexes are poorly understood at present and it is difficult to relate observed differences to structural variations. More useful in this respect is the analysis of vicinal $\left({ }^{3} \mathrm{~J}\right)$ coupling constants known to be dependent on $\mathrm{H}-\mathrm{H}$ dihedral angles through Karplus-like relationships. ${ }^{24}$

Although the differences in conformations of the lateral 5-membered chelate rings for bis- and mono-macrocyclic complexes in the solid state are rather obvious, associated variations in the values of $\mathrm{N}_{\text {amide }}-\mathrm{C}-\mathrm{C}-\mathrm{N}_{\text {amine }}$ torsion angles are not so pronounced (see Figure $\mathrm{S} 2$ in the Supporting Information). Torsion angles are smaller in 'half-envelope' conformations characteristic of $\mathrm{ML}^{14 \mathrm{M}}$ as compared to those in gauche conformations characteristic of $\mathrm{M}_{2} \mathrm{~L}^{14 \mathrm{~B}}$ by $4.7^{\circ}$ for nickel(II) and by $5.8^{\circ}$ for palladium(II), being lower for nickel species in both cases. As concerns NCCC torsion angles in 6-membered trimethylenediamine chelate rings, these are also lower for nickel species but, in contrast, these angles are larger in the mono- as compared to bis-compounds by $7.2^{\circ}$ for nickel(II) and $1.8^{\circ}$ for palladium(II).

The experimental values of the vicinal coupling constants between protons in these rings (Table S7 in the Supporting Information) actually reveal differences, though rather small. The data for all four compounds can be described more or less satisfactorily by modified Karplus curves with coefficients different for 5- and 6-membered chelate rings (Figure S7 in the Supporting Information). So, the trends in variation of the vicinal constants are consistent with those expected based on crystallographic data, i.e. conformational differences observed in the solid state are likely retained in solution. More definite conclusions can hardly be drawn because of the uncertainties in the location of hydrogen atoms, the rather narrow range of variation of torsion angles not exceeding $10^{\circ}$ and limited precision of the experimental $\mathrm{J}$ values $(c a .0 .5 \mathrm{~Hz})$. 
Electronic Absorption Spectra. Electronic absorption spectra of the compounds under consideration in aqueous solution are presented in Figure S8 in the Supporting Information. In all cases d-d absorption bands in the spectra of the bis-macrocyclic complexes are bathochromically shifted $\left(19.1 \times 10^{3}\right.$ vs. $19.8 \times 10^{3} \mathrm{~cm}^{-1}$ for copper, $21.5 \times 10^{3}$ vs. $21.7 \times 10^{3} \mathrm{~cm}^{-1}$ for nickel and $33.0 \times 10^{3}$ vs. $33.8 \times 10^{3} \mathrm{~cm}^{-1}$ for palladium) and characterized by increased extinction coefficients per one metal ion as compared to those of the mono-macrocyclic analogues. ${ }^{17,25}$

In the case of the copper(II) species d-d bands are well described by a single Gaussian function and the shift of the absorption maximum is in agreement with elongation of $\mathrm{Cu}-\mathrm{N}$ bonds in the bis-macrocyclic complex. On the contrary, absorption bands of the nickel(II) complexes are clearly asymmetric, indicating overlap of several d-d transitions, ${ }^{26}$ the shape of the bands being different for $\mathrm{Ni}_{2} \mathrm{~L}^{14 \mathrm{~B}}$ and $\mathrm{NiL}^{14 \mathrm{M}}$. A composite structure of the d-d band is observed also for $\mathrm{PdL}^{14 \mathrm{M}}$ but in the case of $\mathrm{Pd}_{2} \mathrm{~L}^{14 \mathrm{~B}}$ its high-energy part is masked by an intense charge-transfer band. Increased contribution of the latter is likely responsible for both red shift of the absorption maximum and the growths of intensity for the bis-macrocyclic palladium(II) complex. As concerns copper(II) and nickel(II) species, the growths of the absorption intensity for $\mathrm{M}_{2} \mathrm{~L}^{14 \mathrm{~B}}$ probably reflects the significantly larger deviations of the chromophores from planarity characteristic of the bis-macrocyclic complexes (vide supra).

Electrochemistry. The results of our cyclic voltammetry study on the dicopper(II) complex are in agreement with literature data. ${ }^{7}$ In contrast, we did not observe resolved redox processes for the bis-macrocyclic nickel(II) complex - only one anodic and one cathodic peak were present on cyclic voltammograms of $2-\mathrm{Ni}$ with $\mathrm{E}_{1 / 2}$ value of $0.57 \mathrm{~V}$ vs. $\mathrm{SCE}(0.1 \mathrm{M}$ $\left.\mathrm{NaClO}_{4}\right)$. This value is very close to that for the mono-macrocyclic analogue $(0.58 \mathrm{~V}) .^{22}$ However, the considerably increased, as compared to $\mathrm{NiL}^{14 \mathrm{M}}$, peak-to-peak separation $(110 \mathrm{vs}$. $65 \mathrm{mV}$ at scan rate $50 \mathrm{mV} / \mathrm{s}$ ) suggests the existence of a difference in redox potentials of the two metal centers in $\mathbf{2 - N i}$, though much smaller than for dicopper analogue. At the same time, 
similarly to polyamine analogues, ${ }^{27}$ the dioxomacrocyclic palladium(II) complexes in the absence of the halide ions do not oxidize within accessible potential limits.

\section{CONCLUSIONS}

Although all the bis-dioxocyclam complexes studied in this work possess the overall 'stretched' conformation, they demonstrate a number of interesting structural variations: $(i)$ the conformations of the 14-membered subunits included in the bis-complexes are considerably different from those in the corresponding mono-macrocyclic compounds; (ii) the structure of the binuclear compounds is more sensitive to the nature of the metal ion. Comparison with the openchain analogues supports the rather general character of these effects.

The primary reason of these distinctions is, in our opinion, the non-specific effect of the substituent at the apical position of the malonamide chelate ring (the second subunit in binuclear complexes) which induces 'folding' of this ring and conformational changes in the adjacent 5membered chelate cycles. It seems likely that the tolerance to violations of planarity of the coordinated amide fragment, higher for $\mathrm{d}^{9} \mathrm{Cu}$ (II) ion and lower for $\mathrm{d}^{8} \mathrm{Ni}$ (II) and $\mathrm{Pd}(\mathrm{II})$ ions, may be important in explaining the metal-dependent structural variations in the binuclear complexes.

The peculiarity of the bis-macrocyclic copper(II) complex is the ability of crystallization in two forms different in solvent content. On the one hand, these forms are characterized by a close similarity of unit cell parameters and of the structure of constituting elements - water bridged columns of $\mathrm{Cu}_{2} \mathrm{~L}^{14 \mathrm{~B}}$ molecules. On the other hand, linking between these columns and the resulting structure of water aggregates is rather different: $1 \mathrm{D}$-chains for $\mathrm{Cu}_{2} \mathrm{~L}^{14 \mathrm{~B}} \cdot 9 \mathrm{H}_{2} \mathrm{O} v s$. 2D-layers for $\mathrm{Cu}_{2} \mathrm{~L}^{14 \mathrm{~B}} \cdot 12 \mathrm{H}_{2} \mathrm{O}$.

Not unexpectedly, crystal structures of the four-coordinate nickel(II) and palladium(II) complexes are quite different from that of copper(II) complexes including coordinated water molecules. However, the principally different packing and structure of the H-bonded water 
aggregates for $\mathrm{Ni}_{2} \mathrm{~L}^{14 \mathrm{~B}} \cdot 12 \mathrm{H}_{2} \mathrm{O}$ and $\mathrm{Pd}_{2} \mathrm{~L}^{14 \mathrm{~B}} \cdot 12 \mathrm{H}_{2} \mathrm{O}$ (2D-layers $v s$. 3D-network) is surprising, taking into account the close similarity in the molecular structure of these complexes.

\section{ASSOCIATED CONTENT}

\section{Supporting Information}

Calculated and experimental deviations of the metal ion from the mean $\mathrm{N}_{4}$-plane, details of the conformations of the 5-membered chelate rings, parameters of hydrogen bonds, parameters of ${ }^{1} \mathrm{H}$ NMR spectra and Karplus plots for vicinal coupling constants, additional drawings of the crystal structures, and electronic absorption spectra. This material is available free of charge via the Internet at http://pubs.acs.org. CCDC-1049035 (for 1a-Cu $\left(\mathrm{Cu}_{2} \mathrm{~L}^{14 \mathrm{~B}} \cdot 9 \mathrm{H}_{2} \mathrm{O}\right)$ ), -1049036 (for 1b$\mathbf{C u}\left(\mathrm{Cu}_{2} \mathrm{~L}^{14 \mathrm{~B}} \cdot 12 \mathrm{H}_{2} \mathrm{O}\right)$ ), - 1049037 (for 2-Ni $\left(\mathrm{Ni}_{2} \mathrm{~L}^{14 \mathrm{~B}} \cdot 12 \mathrm{H}_{2} \mathrm{O}\right)$ ), and -1049038 (for 3-Pd $\left.\left(\mathrm{Pd}_{2} \mathrm{~L}^{14 \mathrm{~B}} \cdot 12 \mathrm{H}_{2} \mathrm{O}\right)\right)$ contain the supplementary crystallographic data for this paper. These data can be obtained free of charge from The Cambridge Crystallographic Data Centre via www.ccdc.cam.ac.uk/data_request/cif. 


\section{REFERENCES}

(1) Comprehensive Coordination Chemistry II; McCleverty, J. A., Meyer T. J., Eds.; Pergamon: Oxford, 2003; Vol. 7, 813 pp.

(2) Fenton, D. E.; Okawa, H. In Perspectives on Bioinorganic Chemistry; Hay, R. W., Dilworth,

J. R., Nolan, K. B., Eds.; JAI Press: New York, 1993; Vol. 2, Chapter 2, pp 81-138.

(3) Lindoy, L. F. Chemistry of Macrocyclic Ligand Complexes; Cambridge University Press: Cambridge, 1989.

(4) Khan, A.; Greenman, J.; Archibald, S. J. Curr. Med. Chem. 2007, 14, 2257-2277. De Clercq, E. Nat. Rev. Drug Discov. 2003, 2, 581-587.

(5) Bradshaw, J. S.; Krakowiak, K. E.; Izatt, R. M. Aza-Crown Macrocycles; Wiley: New York, 1993; McAuley, A.; Subramanian, S. Coord. Chem. Rev. 2000, 200-202, 75-103. Chartres, J. D.; Lindoy, L. F.; Meehan, G. V. Coord. Chem. Rev. 2001, 216-217, 249-286. Timmons, J. C.; Hubin, T. J. Coord. Chem. Rev. 2010, 254, 1661-1685.

(6) Tabushi, I.; Taniguchi, Y.; Kato, H. Tetrahedron Lett. 1977, 18, 1049-1052.

(7) Buttafava, A.; Fabbrizzi, L.; Perotti, A.; Seghi, B. J. Chem. Soc., Chem. Commun. 1982, 1166-1167. Fabbrizzi, L.; Forlini, F.; Perotti, A.; Seghi, B. Inorg. Chem. 1984, 23, 807-813. (8) Margerum, D. W.; Ovens, G. D. In Metal Ions in Biological Systems; Sigel, H., Ed.; Marcel Dekker: New York, 1981; Vol. 12, Chapter 3, pp 75-92.

(9) Kimura, E. J. Coord. Chem. 1986, 15, 1-28.

(10) Buttafava, A.; Fabbrizzi, L.; Perotti, A.; Poggi, A.; Seghi, B. Inorg. Chem. 1984, 23, $3917-$ 3922.

(11) Comba, P.; Gavrish, S. P.; Hay, R. W.; Hilfenhaus, P.; Lampeka, Ya. D.; Lightfoot, P.; Peters, A. Inorg. Chem. 1999, 38, 1416-1421. 
(12) Bernhardt, P. V.; Comba, P.; Hambley, T. W.; Massoud, S. S.; Stebler, S. Inorg. Chem. 1992, 31, 2644-2651. Zhu, S.; Luo, Q.; Shen, M.; Dai, A.; Huang, L. Polyhedron 1992, 11, 941946.

(13) Zhang, J.-J.; Luo, Q.-H.; Long, D.-L.; Chen, J.-T.; Li, F.-M.; Liu, A.-D. J. Chem. Soc., Dalton Trans. 2000, 1893-1900.

(14) Zhu, S.; Luo, Q.; Shen, M.; Huang, L. Acta Crystallogr., Sect. C: Cryst. Struct. Commun. 1992, 48, 1926-1929.

(15) Gavrish, S. P.; Lampeka, Ya. D.; Lightfoot, P.; Arion, V. B.; Keppler, B. K.; Wozniak, K. Cryst. Growth Des. 2012, 12, 4388-4396.

(16) Lewis, R. M.; Nancollas, G. H.; Coppens, P. Inorg. Chem. 1972, 11, 1371-1375.

(17) Gavrish, S. P.; Lampeka, Ya. D.; Pritzkow, H.; Lightfoot, P. Dalton Trans. 2010, 39, 77067713.

(18) Lampeka, Ya. D.; Gavrish, S. P.; Hay, R. W.; Eisenblätter, T.; Lightfoot, P. J. Chem. Soc., Dalton Trans. 2000, 2023-2029.

(19) Altomare, A.; Cascarano, G.; Giacovazzo, C.; Guagliardi, A. J. Appl. Crystallogr. 1993, 26, $343-350$.

(20) Sheldrick, G. M. SHELXTL 5.1; Bruker AXS: Madison, WI, 1998.

(21) Budzelaar, P. H. M. gNMR, Ivory Soft; Cherwell Scientific Publishers: Oxford, 1996.

(22) Gavrish, S. P.; Lampeka, Ya. D. J. Coord. Chem. 1996, 38, 295-303.

(23) Winkler, F. K.; Dunitz, J. D. J. Mol. Biol. 1971, 59, 169-182.

(24) Günther, H. NMR Spectroscopy. An Introduction; Wiley: Chichester, 1980.

(25) Gavrish, S. P.; Lampeka, Ya. D.; Lightfoot, P. Inorg. Chim. Acta 2004, 357, 1023-1030.

(26) Lever, A. B. P. Inorganic Electronic Spectroscopy, 2-nd ed.; Elsevier Science: Amsterdam, 1984.

(27) Blake, A. J.; Gould, R. O.; Hyde, T. I.; Schröder, M. J. Chem. Soc., Chem. Commun. 1987, 431-433. 


\section{For Table of Contents Use Only}

\section{Metal-Dependent Structural Variations and the Peculiarities of Hydrogen-Bonded Networks in the Highly Hydrated Copper(II), Nickel(II) and Palladium(II) Complexes of Bis-Dioxocyclam}

Sergey P. Gavrish, ${ }^{\dagger}$ Yaroslaw D. Lampeka, ${ }^{* \dagger}$ and Philip Lightfoot ${ }^{\star}$

Bis-dioxocyclam complexes $\mathrm{M}_{2} \mathrm{~L}^{14 \mathrm{~B}}\left(\mathrm{M}=\mathrm{Cu}^{\mathrm{II}}, \mathrm{Ni}^{\mathrm{II}}, \mathrm{Pd}^{\mathrm{II}}\right)$ crystallize as highly hydrated solids with dimensionality of water aggregates in the crystal structures ranging from 1 to 3 . Their molecular structure reveals much stronger dependence on the metal ion as compared to monomacrocyclic analogues.

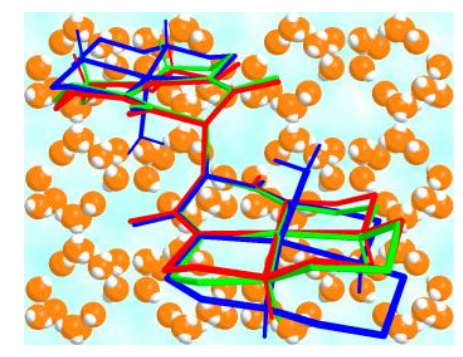

